\title{
Organizing the health sector for response to disasters
}

\author{
Organizando o setor saúde para responder a desastres
}

Kimberley Shoaf ${ }^{1}$

\footnotetext{
${ }^{1}$ Division of Public Health, Department of Family and Preventive Medicine, University of Utah. 375 Chipeta Way, Ste A. 84108 Salt Lake City Utah USA. kimberley.shoaf@utah.edu
}

\begin{abstract}
Each year millions of people around the world are affected by natural and manmade disasters. The consequences of natural disasters in terms of health are complex. Disasters directly impact the health of the population resulting in physical trauma, acute disease, and emotional trauma. Furthermore, disasters may increase the morbidity and mortality associated with chronic and infectious diseases due to the impact on the health system. The health sector must be organized for adequate preparedness, mitigation, response and recuperation from a plethora of potential disasters. This paper examines the various potential impacts of disasters on health, the components of the health sector and their roles in emergency medical care and disaster situations, as well as the coordination and organization necessary within the system to best meet the health needs of a population in the aftermath of a disaster.
\end{abstract}

Key words Disasters, Emergency medical care, Organization and administration, Health system
Resumo A cada ano, milhões de pessoas são afetadas por desastres em todo o mundo, sejam eles naturais ou promovidos pelo homem. As consequências dos desastres naturais para a saúde são complexas. Os desastres impactam diretamente na saúde da população, resultando em danos físicos, doenças agudas e traumas emocionais. Além disso, podem aumentar a morbidade e a mortalidade associada às doenças crônicas e infecciosas, dado o impacto resultante no sistema de saúde. O setor saúde deve estar organizado para a preparação, a mitigação, a resposta e a recuperação para uma miríade de potenciais desastres. O presente artigo explora os vários possiveis impactos dos desastres para a saúde, os componentes do setor saúde e os seus papéis na medicina de emergência e de desastres, da mesma forma, aborda a coordenação e a organização necessária dentro do sistema de saúde para melhor alcançar as necessidades de uma população em um desastre.

Palavras-chave Desastres, Medicina de emergência, Organização e administração, Sistema de saúde 


\section{Introduction}

Each year millions of people are affected by natural and manmade disasters around the world. Between 2002 and 2011, almost 7000 disasters were reported around the world ${ }^{1}$. In that same time period, more than 1.2 million people lost their lives in tornados, hurricanes, heavy rains, earthquakes and tsunamis. More than 2.5 million people have found themselves homeless, economically impacted, or injured because of these disasters. Indeed, disasters would not be 'disastrous' if it were not for their effect on the human population.

The health consequences of natural disasters are complex. Disasters directly impact the health of the population resulting in physical trauma, acute disease, and emotional trauma. In addition, disasters may increase the morbidity and mortality associated with chronic diseases and infectious diseases through the impact on the health system.

The Health Sector must be organized to prepare for, mitigate against, respond to, and recover from a myriad of potential disasters. This paper will explore the various potential health impacts of disasters, the components of the health sector and their roles in emergency and disaster health, as well as the coordination and organization necessary within the system to best meet the health needs of a population in a disaster.

\section{Health effects of disasters}

The health effects of disasters include short and long-term consequences, injuries and illnesses, and both physical and emotional impacts. These health consequences vary both with the type and magnitude of the hazard event as well as with the characteristics of the population impacted. Earthquakes and tsunamis are the deadliest of hazard events, with more 2300 deaths per event during the period 2002-2011. These are followed by extreme temperature events at 620 deaths per event ${ }^{1}$.

\section{Direct Health Effects}

Direct health effects are those effects which result directly from the force of the hazard, such as injuries which result from ground motion in earthquakes or wind in hurricanes/cyclones. Different hazards result in a variety of direct health effects. Earthquakes can result in very large numbers of fatalities. However, both the number and the rate of fatalities can vary immensely ${ }^{2,3}$. Earthquakes are not only deadly, but also often result in large numbers of individuals with minor to severe injuries. Indeed, in the moderate Northridge earthquake in California in 1994, only thirty-three deaths from injuries resulted, but more than $8 \%$ of households in Los Angeles County reported that at least one person was injured in their household ${ }^{4}$. Extrapolating to the 3 million households in Los Angeles County at the time would result in a minimum of 240,000 injured people. Most of those reported injuries were mild, not resulting in medical care. However, 138 people were hospitalized, more than 9000 people were seen in hospital emergency rooms, and 18,000 reported seeking medical care from non-hospital based health care sources ${ }^{4}$. Again, as Table 1 demonstrates the ratio of injuries to deaths can vary a great deal from earthquake to earthquake $e^{2,5}$.

Extreme temperature events are the second most fatal type of disaster. These include both heat and cold events, with cold events being more deadly than heat events. Kunkel et al. ${ }^{6}$ report that in a review of the literature, extreme cold events in the United States resulted in 770 deaths per year and extreme heat events in the US resulted

Table 1. Distribution of Injuries Across Five Earthquakes.

\begin{tabular}{lccrrr}
\hline \multicolumn{1}{c}{ Earthquake } & $\begin{array}{c}\text { EQ } \\
\text { Magnitude }\end{array}$ & $\begin{array}{c}\text { Fatalities/ } \\
\mathbf{1 0 0 , 0 0 0} \\
\text { population }\end{array}$ & $\begin{array}{c}\text { Hospitalized/ } \\
\mathbf{1 0 0 , 0 0 0} \\
\text { population }\end{array}$ & $\begin{array}{r}\text { Treat and } \\
\text { Release/100,000 } \\
\text { population }\end{array}$ & $\begin{array}{c}\text { Injury } \\
\text { Rate/100,000 } \\
\text { population }\end{array}$ \\
\hline Whittier Narrows, CA (1987) & 5.9 & .03 & Data Not Available & Data Not Available & 800 \\
Loma Prieta, CA (only Santa & 6.9 & 2.1 & Data Not Available & 106 & 700 \\
Cruz County) (1989) & 6.7 & .37 & 1.56 & 80 & 2733 \\
Northridge, CA (1994) & 6.9 & 274 & 315 & Data Not Available & 2150 \\
Kobe, Japan (1995) & 6.2 & 401 & Data Not Available & Data Not Available & 1572 \\
Quindio, Colombia (1999) & & & & & \\
\hline
\end{tabular}

Adapted from Seligson and Shoaf ${ }^{2}$. 
in 384 deaths per year. The elderly are particularly sensitive to temperature extremes, particularly extreme heat events? ${ }^{7}$. These extreme temperature events are often complicated by loss of electricity. Extreme cold events with electrical outages often have increased mortality, not just due to exposure to cold, but also from fires from the use of candles and carbon monoxide poisoning from improper use of generators and heat sources.

While flooding events are not the deadliest of disasters, they have significant health effects, both in the long and short-term. The most common and obvious cause of mortality in floods is due to drowning. There is however some evidence, particularly in developing countries, that diarrheal disease following flooding events may also result in excess mortality. Other health impacts from floods include injuries and illness. ${ }^{9}$. A study in France following a flood event suggested that about $6 \%$ of households reported a mild to moderate injury related to the flood ${ }^{8}$. This number is similar to that seen in the Northridge Earthquake and about half of the $17 \%$ of households reporting injuries in a study of households in New Orleans following Hurricane Katrina ${ }^{10}$. In addition to mild to moderate injuries, illnesses may increase following flooding events. Gastrointestinal illness, particularly diarrheal disease may increase. In developed nations, this increase is generally small and usually due to non-specific organisms ${ }^{8}$. In less developed nations, the increase can be quite significant and due to multiple organisms including paratyphoid and cryptosporidia ${ }^{8}$.

Both geologic hazards such as earthquakes and meteorological events such as rainfall can result in the movement of landmasses. Landslides of either origin can have devastating effects on the population. Perhaps one of the most noted large landslides is the 1970 Nevado Huascarán movement in Peru. This landslide resulted in a realistic estimated 6000 deaths in the rural province of Yungay in the Department of Ancash, Peru. A recent event in Brazil resulted from a large tropical storm that dumped $180 \mathrm{~mm}$ of rain in 30 hours. This storm created large mudflows in multiple areas and resulted in 30,000 persons displaced from their homes, more than 700 injuries and $845 \mathrm{im}$ mediate deaths ${ }^{11}$.

\section{Secondary Health Effects}

Secondary health effects can result in any of the disaster types discussed above due to the impact on the living conditions of the survivors as well as the ability of the health care and public health sector to remain viable. The majority of the illness that results from disasters is not a direct result of the disaster, but rather a result of the disaster damaging the pre-existing infrastructure that prevents such illness in normal times. For example, diarrheal disease, described above, results from illness-causing organisms being introduced into the drinking water. It also can result from food being improperly stored or prepared or individuals living in extremely close quarters in shelters. Following Hurricane Katrina in 2005, more than 25,000 survivors were housed in the Astrodome-Reliant Center complex in Houston, Texas. An outbreak of gastrointestinal disease occurred, with an epidemiologic pattern and laboratory results suggestive of person-person transmission of Norovirus ${ }^{12}$. Similarly, respiratory diseases are quite common in crowded shelters following disasters. Acute respiratory illness can increase as much as 4 -fold over pre-disaster rates in shelters. This has been seen following Hurricane Mitch in Nicaragua, the Banda Aceh tsunami in 2004 and the 2005 earthquake in Pakistan. Vector-borne diseases are also a possibility. Following Hurricane Mitch in Honduras in 1999, a significant increase in Dengue fever, including hemorrhagic forms were noted in two waves ${ }^{13}$. Watson et al. ${ }^{14}$ suggest that this increase is most likely a result of the interruption of normal vector control activities as well as changes to the environment of the vector. Other vector-borne diseases such as Malaria are also possible?

\section{Mental Health Effects}

Thus far we have only discussed physical impacts of disasters, however mental health impacts are at least as prevalent in the post-disaster setting as physical health impacts. In a review of the disaster mental health literature, Norris et al. ${ }^{15}$. demonstrate that both short and long-term mental health impacts occur following disasters. These impacts include both non-specific distress, that generally resolves itself over time, and longer term psychopathologies such as Post-Traumatic Stress Disorder (PTSD) and Depression. The disaster mental health literature has also shown that longer-term, clinically significant disorders are associated with greater exposure to disaster impacts, including being injured, losing a loved one, or being displaced from one's home as a result of the disaster ${ }^{16-18}$. Rates of distress in the immediate aftermath of a disaster can range from $30 \%$ of the population ${ }^{19,20}$ to as high as $90 \% \%^{15,21,22}$. Longer-term mental health effects can range from $10 \%-50 \%$ of the impacted population ${ }^{15,17,23}$. 


\section{Components of the health system}

The health system on a global level is currently undergoing significant changes. As we explore the components of the health system as they relate to disasters, we will broadly define the "health care system" as those actors and organizations that provide health care to individuals. These actors have historically been seen as providing mostly curative care, but more and more are engaged in preventive care as well. We will define the "public health system" as those actors and organizations that are responsible for ensuring an environment that is conducive to health for the population as a whole. These actors are traditionally preventive in nature and generally work to prevent disease and promote health on a population, rather than an individual level.

In some countries, the division between these two sets of actors is well-defined. For example in the United States, public health is provided primarily by governmental public health agencies at the local, state and federal level. Health Care on the other hand is primarily provided by a variety of private providers, both for profit and non-profit. Public health care is primarily for low-income individuals and may be provided by public clinics and hospitals or in private hospitals and paid for by public funds (either contracted by the government or through public insurance). In Canada, Health Canada governs the provision of health care (through public insurance for necessary health care provided by private providers) whereas the Public Health Agency of Canada promotes health and prevents injury and illness through population-based programs and services. In other countries the public health system and the health care system are combined into a single system. In Brazil, the Ministry of Health governs both the health care system and the public health system with much of the health care being provided by public hospitals and primary health care providers.

In preparing for, mitigating against, responding to, and recovering from disasters both the health care system and the public health system play a significant role. The health care system is necessary to meet the immediate and longer-term health needs of the population as generated by the disaster. The public health system is necessary to assess, monitor, and survey both the health problems that result from the disaster but also to identify and assess the availability and procure the resources to deal with the problems.

\section{Health Care System}

In disasters, a large number of injured individuals can quickly overwhelm a health care system. Health care systems need to include a number of components in order to manage both the daily influx of injured and acutely ill as well as the surge of patients during a disaster. These components include: prehospital care and transportation of the injured; emergency medical care including triage; and trauma care, including definitive care and surgery (Figure 1).

\section{Prehospital care and transport}

In many instances the prompt provision of emergency care and rapid movement of injured victims from the scene of injury to a health-care facility can save lives, reduce the incidence of short-term disability and dramatically improve long-term outcomes ${ }^{24-26}$. There are many models of prehospital care systems that provide prompt emergency care and transport of victims. The system may be: national or regional/local systems; provide basic levels of care or more advanced levels of care; community based or hospital based; staffed by paid professionals or volunteers. Regardless of the system, the ability to provide at a minimum life-saving first aid at the scene and quickly and safely transport a victim to emergency medical care is extremely important on a day to day basis, but in a disaster it is essential. Noji et al. ${ }^{26,27}$ recognized in the Armenian earthquake the impact that the lack of any form of prehospital care had on potential survivors in that earthquake in 1988. Almost a third (30\%) of injured survivors in that earthquake received no medical care at the scene and nobody received any advanced medical care such as intravenous fluids or a cervical-spine immobilization. The lack of prehospital care may have contributed to the high mortality in this earthquake. Safar ${ }^{28}$ estimated that in the 1980 earthquake in Italy $25-50 \%$ of those who died did so slowly and could have been saved by life-saving first aid.

Bissell $^{5}$ also found that a prehospital care system may be a component in creating a significant difference in mortality/morbidity ratios in earthquakes. In comparing the Loma Prieta Earthquake in Northern California in 1989, the Northridge Earthquake in Southern California in 1994 and the Kobe, Japan earthquake exactly one year later, Bissell et al. ${ }^{5}$ demonstrated a difference in the injury/death ratio for these three very similar earthquakes. Kobe had injury to death ratios 


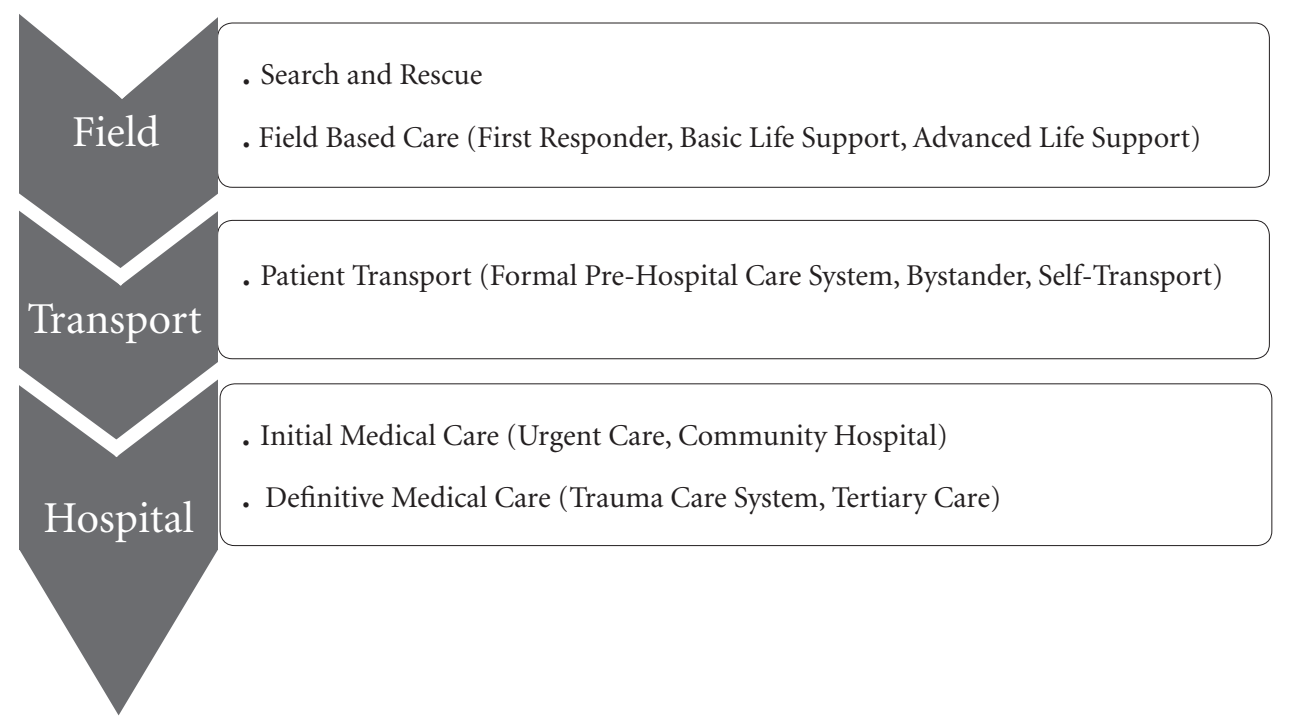

Figure 1. Health Care System (Adapted from Bissell et al. ${ }^{5}$ ).

of 3.2-17.3/1 whereas the California earthquakes had ratios of 56.1 - 150.9 injuries per death. Both California and Japan have a high level of resources available to the population and strong health care sectors. One significant difference between the California health sector and the Kobe Japan health sector is the presence of a strong prehospital care system. This may have been a factor in the higher injury to death ratio in California earthquakes compared to the Kobe Japan earthquake.

\section{Emergency medical care}

Clearly a prehospital care system is only effective if there is competent emergency medical care available at the end of the transport. In reviewing the health care sector in acute disasters in the United States, Stratton and Tyler ${ }^{29}$ noted that the majority of injuries and illnesses following disasters were amenable to ambulatory care. They also noted that the primary entry point for care following a disaster was often the hospital. Following the Northridge earthquake, one-third of households reporting seeking care for their injuries sought care at a hospital ${ }^{4}$.

The majority of acute injuries and illnesses that result from disasters require urgent, if not immediate, medical care to prevent them from becoming life threatening. The medical specialty of emergency medicine was developed early in the second half of the last century to provide this type of medical care. This specialty field of practice is designed to diagnose and manage the acute and urgent aspects of illness and injury ${ }^{30}$. Community hospitals with emergency departments that are available 24/7 and that receive patients from a coordinated prehospital care sector are the basis for emergency care in the United States and many other nations. Following a disaster, they are a primary source of care for the surge of patients. It has been noted that the surge of patients varies from disaster to disaster, but normally starts within the first hours following the event and continues for 24-48 hours ${ }^{29,31}$. Outside medical assistance rarely is available until at least 96 hours following impact. This suggests that community hospitals need to be able to handle the surge of acute patients for at least 96 hours.

While community hospitals are a primary mechanism for meeting this demand, other models exist either alone or in tandem with emergency departments in community hospitals. Brazil has established Emergency Care Units for intermediate-level care for the treatment of less serious injuries or illnesses and the stabilization of more seriously injured, prior to transfer to a tertiary care facility. Another mechanism for providing definitive medical care in disasters is the use of field hospitals. The development of the US National Disaster Medical System had the specific 
aim of providing quick surge capacity to a stricken community ${ }^{32,33}$. This system includes the development of self-supporting medical teams that can quickly provide surge capacity for medical and surgical treatment of disaster victims either at a hospital site or in their stand-alone field hospitals. The system also includes the coordination of transport and receiving hospitals to evacuate patients from overwhelmed and damaged health care facilities in the disaster area.

\section{Trauma care system}

Part of an overall emergency medical care system is the trauma care system to care for those with serious to critical injuries. A Trauma Center is a tertiary care facility that provides trauma care, specializing in the comprehensive diagnosis and treatment for all forms of traumatic injury. The American College of Surgeons designates a hospital as a Level I Trauma Center if it is optimally prepared to manage any type of injury 24 hours a day, 7 days a week. This requires that the center has in-house acute care surgeons, designated operating rooms, available CT scanners, trauma accredited nursing staff, surgical critical care, 24/7 blood bank operation and immediately available subspecialists like neurosurgeons and orthopedic trauma surgeons. To maintain this designation, the center must also participate in trauma prevention programs, have a quality outcomes program, and provide a trauma education and research program. The Trauma Team is comprised of surgeons and advanced practitioners who care for critically ill and injured patients of all ages ${ }^{34}$.

Clearly it is not cost-effective for all hospitals in a region to have this level of trauma care. Research on trauma systems have demonstrated that having a coordinated system of prehospital care, community hospitals with trained emergency medicine specialists as well as designated trauma centers to care for the most critically injured, reduces the mortality from injuries significantly. The system entails conducting triage in the field to identify serious physical injuries that achieve an Injury Severity Score (ISS) of 15 or greater ${ }^{35}$ and transporting these more serious injuries to a designated trauma center.

These trauma centers are tertiary care facilities that have the capacity to provide high levels of complex care for serious physical traumas on a 24/7 basis. When a trauma care system as described here was instituted in Quebec, Canada, mortality from severe trauma decreased over the next decade from $51.8 \%$ in 1992 to $8.6 \%$ in
$2002^{36}$. Appropriate use of an organized trauma system has been demonstrated as effectively assigning the right patients to the right treatment facility in both multi-casualty incidents and disasters $^{37,38}$. Proper assignment of patients to care, based on injury severity should reduce the need for inter-facility transfer and thus decrease the time to definitive care. Time to definitive care has been demonstrated as a significant factor in decreasing injury mortality ${ }^{39}$.

\section{Mental health care}

Like the physical health care system, the mental health care system has a number of levels of care, from self-care and informal community care, through community based professional services and community hospital-based psychiatric services to in-patient psychiatric hospitals. While the higher levels of care are primarily focused on curative services, more and more preventive care is being provided as well ${ }^{40}$. All of the levels of care are required in responding to disasters to meet the immediate mental health needs, prevent the onset of more serious mental health issues through early detection and treatment, and to provide definitive care to those who are affected by long-term psychopathologies such as PTSD and depression. Community based care, including the informal sector are particularly needed in the early days following a disaster.

A coordinated mental health system which includes psychological triage of affected persons and referral to appropriate levels of mental health care has been developed and recently adopted in parts of the United States. PsySTART ${ }^{18,41}$ provides for situational awareness of "at risk" individuals and linkage to follow on care. In a surge environment of many "at risk" individuals, the PsySTART system uses a triage algorithm to prioritize those individuals who need be seen first and those who need to be seen next or can be referred for later assessment after the initial surge. The algorithm is based on the degree of exposure to the disaster and assesses items such as severe injury to self; loss of family member; separation of a child from parents; seeing and/or hearing dead bodies or people crying for help. Based on the algorithm, those at higher risk are referred for psychological assessment and potential treatment while those at lower risk are provided with psychological first aid and assigned to a "wait and see" status. This allows for better management and allocation of limited psychological resources in the acute phase of the disaster. 


\section{Public Health System}

According to the World Health Organization, "Public health refers to all organized measures (whether public or private) to prevent disease, promote health, and prolong life among the population as a whole. Its activities aim to provide conditions in which people can be healthy and focus on entire populations, not on individual patients or diseases" ${ }^{42}$. The three main public health functions are:

- The assessment and monitoring of the health of communities and populations at risk to identify health problems and priorities.

- The formulation of public policies designed to solve identified local and national health problems and priorities.

- The assurance that all populations have access to appropriate and cost-effective care, including health promotion and disease prevention services.

In the US, the three public health functions have been further delineated into 10 Essential Services and visualized in a wheel (Figure 2$)^{43}$. We may say that for public health professionals the entire population is their patient as they monitor and diagnose the health concerns of entire communities and promote healthy practices and behaviors to ensure that populations stay healthy.

During disasters, public health performs the same functions as they do on a daily basis. Indeed maintaining existing population based health strategies such as immunization, vector control,

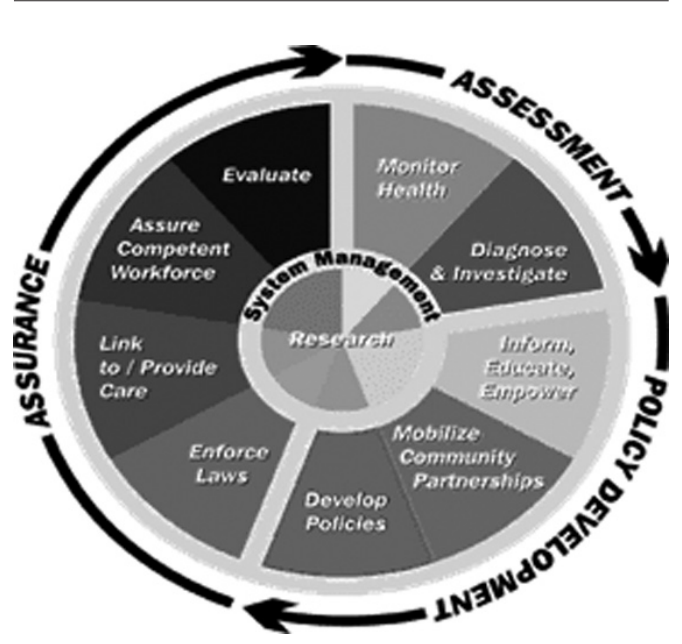

Figure 2. Ten Essential Services of Public Health. and assurance of sanitation and food/water quality may be the most important factors in reducing morbidity and mortality in disasters ${ }^{44}$. Beyond maintaining existing strategies, the assessment and assurance roles may encompass new parameters. Assessment in the early hours of a disaster include conducting rapid health needs assessments to determine both the immediate health impacts of the disasters as well as the potential environmental impacts which could pose threats to the health of the population over time $e^{45,46}$. A key assessment strategy in the public health arsenal, which is particularly important following disaster, is conducting surveillance for injuries, diseases, and potential risk factors for injury and disease. Assurance strategies include ensuring that mass gathering and feeding sites, such as evacuation shelters provide a safe and healthy environment. They also monitor and maintain vector control activities; provide education in regards to safety and health protection; provide health advisories to the public and the health care community to reduce the risk of illness and injury and to ensure proper treatment; and enact and enforce laws and policies which protect the health of the population ${ }^{47}$. A key role that public health plays following a disaster is coordination of the response of the entire health system to ensure that health needs of the entire population are met. Figure 3 provides a visual example of some of the responsibilities of public health as they relate to health care providers and other emergency response sectors ${ }^{48,49}$.

\section{Coordination of the health system}

In order for the health system to meet the surge in demands generated by disasters, they need to be organized and prepared. Because of the critical services they provide to the population, they cannot afford to halt operations before, during or following a hazard event. Indeed, in spite of potential damage to infrastructure and loss of availability of personnel, the health system not only needs to maintain their capacity, but also increase it to meet the surge in demand resulting from the hazard. Coordination within the health sector as well as between the health sector and other emergency response players is essential to meet these needs. Good coordination means less gaps and overlaps in the work of the response agencies. It strives for a needs-based, rather than capacity-driven, response. It aims to ensure a coherent and complementary approach, identifying ways to work together for better collective results. 


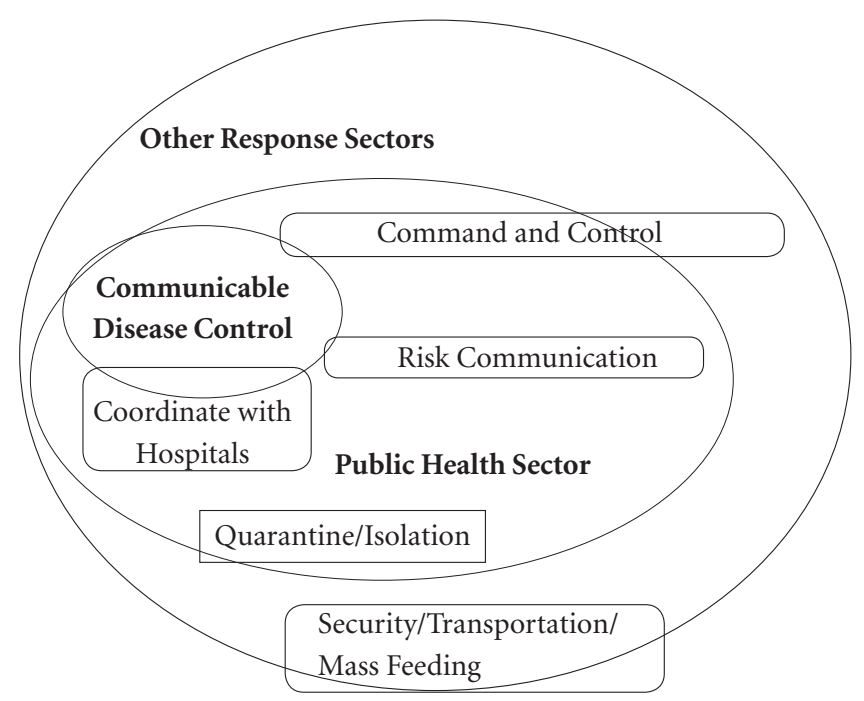

Figure 3. Responsibilities of the Public Health Sector vis a vis Hospitals and other Response Sectors (adapted from Communicable disease alert and response for mass gatherings, WHO $2008^{49}$ ).

There is any number of examples of coordination, but two examples of coordination in disaster response stand out. The first is the cluster system utilized when United Nations Agencies are involved in an international disaster response. Clusters are groups of humanitarian organizations (UN and non-UN) working in the main sectors of response, e.g. shelter and health. They are created when a clear need exists within a sector and when there are numerous actors within sectors. Clusters provide a clear point of contact and are accountable for adequate and appropriate assistance to the affected population. Clusters create partnerships between international humanitarian actors, national and local authorities, and civil society ${ }^{50}$. Within the Cluster approach there is an organized approach to each sector's responsibilities and the interactions between sectors. However, the success of coordination within a sector is not always guaranteed. While the Cluster approach was developed in 2004, the largest implementation of it was in response to the earthquake in Haiti ${ }^{51}$. According to O'Connor ${ }^{51}$ the implementation fell quite short of successful. The system allows for inter-cluster communication, however, there is no formal decision-making process, nor any mechanism for mandating collaboration. During the Haiti response, there were 400 Non-Governmental Organizations (NGOs) working within the Shelter
Cluster. Without any clear decision-making system in place, this results in chaos, not success.

In the United States, the National Incident Management System (NIMS) has been adopted as a means of coordination of emergency response. The National Response Framework ${ }^{52}$ outlines the system whereby disasters are managed at a $\mathrm{Na}$ tional level. "It is built upon scalable, flexible, and adaptable coordinating structures to align key roles and responsibilities across the Nation, linking all levels of government, nongovernmental organizations, and the private sector" ${ }^{22}$. Similar to the Clusters in the UN system, The National Response Framework outlines the various functions (Emergency Support Functions) that are necessary in a disaster response and assigns a lead Federal agency to lead that function. Emergency Support Function \#8 is Public Health and Medical Services, for which the Department of Health and Human Services is the lead agency.

The National Response Framework also outlines how the various levels of government (Federal, State, Local) interact and are based on the Incident Command System. The Incident Command System (ICS) is a management system which utilizes standardized terminology and positions to coordinate the response to a disaster. ICS was first put forward as a methodology for managing disaster responses by firefighters in California fight- 
ing wildfires. In the 1970s they realized that a key element hindering their effective response to large wildfires was a lack of coordination and communication. They established FIRESCOPE ${ }^{53}$ and standardized the use of an incident command system for response to all hazards for the fire service.

The Incident Command System is a management system used to achieve command and control within an organization and seamless inter-agency coordination during any type of emergency event. ICS is user-friendly and applicable across a wide spectrum of incidents. Key features include the use of the following: a clearly defined chain of command, common nomenclature for key management positions, defined management sections, modular organization, management by objectives and use of specifically described emergency response functional roles ${ }^{54}$. While ICS was originally used by the fire service, under the $\mathrm{Na}$ tional Incident Management System, its use is required for all agencies responding to disasters in the United States. Adaptations of ICS have been made for Public Health ${ }^{54,55}$ and for Health Care ${ }^{55,56}$ in order to facilitate their use of the system and work collaboratively with other emergency management agencies during a disaster response.

Like at the Federal level under the National Response Framework, at the local level ICS coordinates the efforts of the various sectors through a Multiagency Coordination System (MACS) often located in an Emergency Operations Center (EOC). Emergency Management (or Law Enforcement) takes the lead role in the coordination effort, but each agency in the jurisdiction has a seat at the table. Both public health and health care should be represented at the table. Clearly not every single health care provider in a commu- nity can be present in the MACS/EOC during an emergency response. As the governmental agency at the local level with responsibility for protecting the health of the population, public health should serve as the lead agency within the MACS/EOC for health. That then puts the onus on public health to ensure coordination and collaboration within the health sector.

One model that is emerging in the United States for coordination within the health sector is the utilization of health care coalitions. These coalitions may have come together for other purposes, but can also be useful during an emergency response. This coalition can provide a mechanism for sharing information between health care organizations and can provide a representative of the group to public health (or directly to the $\mathrm{MACS} / \mathrm{EOC})^{57}$.

\section{Conclusion}

Regardless of the system employed, it is essential that the health sector coordinate their emergency response efforts both internally and externally with other emergency response agencies. In order to do this effectively there needs to be a system in place which allows for coordination and collaboration at the planning, response and recovery stages of a disaster across all organizations and agencies in the jurisdiction. An adage that is too oft repeated is that the time to share business cards is not in the middle of a disaster. The health system needs to step up now and be counted as part of an organized disaster planning, response and recovery system. 


\section{References}

1. International Federation of Red Cross and Red Crescent Societies. Focus on forced migration and displacement. Geneva: International Federation of Red Cross and Red Crescent Societies; 2012.

2. Seligson H, Shoaf K. Human Impacts of Earthquakes. New Directions in Civil Engineering. Earthquake Engineering Handbook. Cleveland: CRC Press; 2002.

3. Peek-Asa C, Ramirez M, Seligson H, Shoaf K. Seismic, structural, and individual factors associated with earthquake related injury. Inj Prev 2003; 9(1):62-66.

4. Shoaf KI, Sareen HR, Nguyen LH, Bourque LB. Injuries as a Result of California Earthquakes in the Past Decade. Disasters 1998; 22(3):218-235.

5. Bissell RA, Pinet L, Nelson M, Levy M. Evidence of the Effectiveness of Health Sector Preparedness in Disaster Response: The Example of Four Earthquakes. Fam Community Health 2004; 27(3):193-203.

6. Kunkel KE, Pielke Junior RA, Changnon SA. Temporal Fluctuations in Weather and Climate Extremes That Cause Economic and Human Health Impacts: A Review. [accessed $2014 \mathrm{Feb}$ 12]. Available at: http://journals.ametsoc.org/doi/pdf/10.1175/15200477(1999)080<1077:TFIWAC >2.0.CO;2

7. Medina-Ramón M, Zanobetti A, Cavanagh DP, Schwartz J. Extreme temperatures and mortality: assessing effect modification by personal characteristics and specific cause of death in a multi-city case-only analysis. Environ Health Perspect 2006; 114(9):1331-1336.

8. Ahern M, Kovats RS, Wilkinson P, Few R, Matthies F. Global Health Impacts of Floods: Epidemiologic Evidence. Epidemiol Rev 2005; 27(1):36-46.

9. Freitas CM De, Ximenes EF. Enchentes e saúde pública - uma questão na literatura científica recente das causas, consequências e respostas para prevenção e mitigação Floods and Public Health - a review of the recent scientific literature on the causes, consequences and responses t. Cien Saude Colet 2012;17(6):1601-1615.

10. Kelley M, Perman J, Shoaf KI. Using community wellness as an indicator of resilience after Hurricane Katrina. In: Returning to Katrina: Bringing Hurricane Katrina Research Back to the Community. Long Beach: WCP; 2010.

11. Monteiro Tavares Pereira B, Morales W, Galesso Cardoso R, Fiorelli R, Pereira Fraga G, Briggs SM. Lessons learned from a landslide catastrophe in Rio de Janeiro, Brazil. Am J Disaster Med 2013; 8(4):253-258.

12. Murray KO, Kilborn C, DesVignes-Kendrick M, Koers E, Page V, Selwyn BJ, Shah UA, Palacio H. Emerging disease syndromic surveillance for Hurricane Katrina evacuees seeking shelter in Houston's Astrodome and Reliant Park Complex. Public Health Rep 2009; 124(3):364-371.

13. Corrales A. Hurricane Mitch: A Central American Disaster. In: Corrales A. Natural HazardsWorkshop. Boulder: Natural Hazards Center; 1999.

14. Watson JT, Gayer M, Connolly MA. Epidemics after natural disasters. Emerg Infect Dis 2007; 13(1):1-5.

15. Norris FH, Friedman MJ, Watson PJ, Byrne CM, Diaz E, Kaniasty K. 60,000 disaster victims speak: Part I. An empirical review of the empirical literature, 1981-2001. Psychiatry 2002; 65(3):207-239.
16. Norris FH, Friedman MJ, Watson PJ. 60,000 disaster victims speak: Part II. Summary and implications of the disaster mental health research. Psychiatry 2002; 65(3):240-260.

17. Galea S, Nandi A, Vlahov D. The epidemiology of post-traumatic stress disorder after disasters. Epidemiol Rev 2005; 27(1):78-91.

18. Schreiber MD, Yin R, Omaish M, Broderick JE. Snapshot From Superstorm Sandy: American Red Cross Mental Health Risk Surveillance in Lower New York State. Ann Emerg Med 2014; 64(1):59-65.

19. Porter K, Jones L, Cox D, Goltz J, Hudnut K, Mileti D, Perry S, Ponti D, Reichle M, Rose AZ, Scawthorn CR, Seligson HA, Shoaf KI, Treiman J, Wein A. The ShakeOut Scenario: A Hypothetical Mw7.8 Earthquake on the Southern San Andreas Fault. Earthq spectra 2011; 27(2):239-261.

20. Seligson HA, Shoaf KI. Human impacts of earthquakes. In: Earthquake Engineering Handbook. Cleveland: CRC Press; 2003.

21. Davidson JRT, McFarlane AC. The extent and impact of mental health problems after disaster. J Clin Psychiatry 2006; 67(Supl. 2):9-14.

22. Kessler RC, Galea S, Gruber MJ, Sampson NA, Ursano RJ, Wessely S. Trends in mental illness and suicidality after Hurricane Katrina. Mol Psychiatry 2008; 13(4):374-384.

23. Ruggiero KJ, Gros K, McCauley JL, Resnick HS, Morgan M, Kilpatrick DG, Muzzy W, Acierno R. Mental health outcomes among adults in Galveston and Chambers counties after Hurricane Ike. Disaster Med Public Health Prep 2012; 6(1):26-32.

24. Sasser S, Varghese M, Kellermann A, Lormand J. Prehospital trauma care systems. Geneva: WHO; 2005.

25. Sasser SM, Varghese M, Joshipura M, Kellermann A. Preventing death and disability through the timely provision of prehospital trauma care. Bull World Health Organ 2006; 84(7):507.

26. Noji EK, Armenian HK, Oganessian A. Issues of Rescue and Medical Care Following the 1988 Armenian Earthquake. Int J Epidemiol 1993; 22(6):1070-1076.

27. Noji EK, Kelen GD, Armenian HK, Oganessian A, Jones NP, Sivertson KT. The 1988 earthquake in Soviet Armenia: A case study. Ann Emerg Med 1990; 19(8):891-897.

28. Safar P. Resuscitation Potentials in Mass Disasters. Prehosp Disaster Med 2012; 2(1-4):34-47.

29. Stratton SJ, Tyler RD. Characteristics of medical surge capacity demand for sudden-impact disasters. Acad Emerg Med. 2006;13(11):1193-1197.

30. Suter RE. Emergency medicine in the United States: a systemic review. World J Emerg Med 2012; 3(1):5-10.

31. Hick JL, Hanfling D, Burstein JL, DeAtley C, Barbisch D, Bogdan GM, Cantrill S. Health care facility and community strategies for patient care surge capacity. Ann Emerg Med 2004; 44(3):253-261.

32. Bonnett CJ, Peery BN, Cantrill S V, Pons PT, Haukoos JS, McVaney KE, Colwell CB. Surge capacity: a proposed conceptual framework. Am J Emerg Med 2007; 25(3):297-306. 
33. Mahoney LE, Reutershan TP. Catastrophic disasters and the design of disaster medical care systems. Ann Emerg Med 1987; 16(9):1085-1091.

34. What is a Trauma Center.Trauma Care.Carolinas HealthCare System. [accessed 2014 Feb 28]. Available at: http://www.carolinashealthcare.org/trauma-centerdefinition

35. Palmer C. Major trauma and the injury severity scorewhere should we set the bar? Annu Proc Assoc Adv Automot Med. 2007; 51:13-29.

36. Liberman MM, Mulder DSM, Lavoie AP, Sampals JSP. Implementation of a Trauma Care System: Evolution Through Evaluation. J Trauma Inj Infect Crit Care 2004; 56(6):1330-1335.

37. Ammons MAMD, Moore EEMD, Pons PTMD, Moore FAMD, McCroskey BLMD, Cleveland HCMD. The Role of a Regional Trauma System in the Management of a Mass Disaster: An Analysis of the Keystone, Colorado, Chairlift Accident. J Trauma Acute Care Surg 1988; 28(10):1468-1471.

38. May AKM, McGwin GJP, Lancaster LJM, Hardin W, Taylor AJ, Holden S, Davis GG, Rue LW 3rd. The April 8, 1998 Tornado: Assessment of the Trauma System Response and the Resulting Injuries. J Trauma Acute Care Surg 2000; 48(4):666-672.

39. Harrington DT, Connolly M, Biffl WL, Majercik SD, Cioffi WG. Transfer times to definitive care facilities are too long: a consequence of an immature trauma system. Ann Surg 2005; 241(6):961-966. (Discussion, n. 966-968).

40. World Health Organization (WHO). Improving health systems and services for mental health. Geneva: WHO; 2009.

41. King ME, Schreiber MD, Formanski SE, Fleming S, Bayleyegn TM, Lemusu SS. A Brief Report of Surveillance of Traumatic Experiences and Exposures After the Earthquake-Tsunami in American Samoa, 2009. Disaster Med Public Health Prep 2013; 7(3):327-331.

42. World Health Organization (WHO). Public Health. [accessed 2014 Mar 1]. Available at: http://www.who. int/trade/glossary/story076/en/

43. Centers for Disease Control and Prevention (CDC). Public Health System and the 10 Essential Public Health Services - NPHPSP. [accessed 2013 Aug 6]. Available at: http://www.cdc.gov/nphpsp/essentialservices.html

44. Shoaf KI, Rottman SJ. Public Health Impact of Disasters. Aust J Emerg Manag. 2000;15(04):18-20. [accessed 2012 Sep 13]. Available at: http://journals.cambridge. org/abstract_S1049023X00025243

45. Centers for Disease Control and Prevention. Community Assessment for Public Health Emergency Response (CASPER) Toolkit. Atlanta, Georgia; 2012. [accessed 2014 Jun 10]. Available at: http://emergency.cdc.gov/ disasters/surveillance/pdf/casper_toolkit_508 compliant.pdf

46. Rodrigues-Júnior AL. A inteligência epidemiológica como modelo de organização em saúde Epidemiological intelligence as a model of organization in health. Cien Saude Colet 2012; 17(3):797-805.
47. Landesman LY. Public Health Management of Disasters: The Practice Guide. Washington: American public health association; 2001.

48. Utah Department of Health. Utah Health Status Update : Public Health Preparations for the 2002 Olympic Winter Games January 2002 Utah Health Status Update. 2002; (January).

49. World Health Organization (WHO). Communicable disease alert and response for mass gatherings.; 2008. [accessed 2014 Jun 4]. Available at: http://www.who. int/csr/Mass_gatherings2.pdf

50. United Nations General Assembly. General Assembly resolution 46/182.; 1991. [accessed 2014 Mar 11]. Available at: http://daccess-dds-ny.un.org/doc/RESOLUTION/GEN/NR0/582/70/IMG/NR058270.pdf?OpenElement

51. O'Connor M. The U.N. "Cluster System" Is as Bad as It Sounds. Slate. 2011. Available at: http://www. slate.com/articles/news and_politics/dispatches/features/2011/does_international_aid_keep_haiti_poor/ the_un_cluster_system_is_as_bad_as_it_sounds.html. Accessed March 12, 2014.

52. Department of Homeland Security. National Response Framework. Washington DC.; 2008. Available at: http:// www.fema.gov/pdf/emergency/nrf/nrf-core.pdf.

53. Chase RA. FIRESCOPE: a new concept in multiagency fire suppression coordination. Berkeley: U.S. Dept. of Agriculture, Forest Service, Pacific Southwest Forest and Range Experiment Station; 1980.

54. Quereshi K, Gebbie KM, Gebbie EN. A Guide for the Management of Emergencies or Other Unusual Incidents within Public Health Agencies. New York: PHICS; 2006. [accessed 2014 Mar 20]. Available at: http://www.ualbanycphp.org/pinata/phics/guide/default.cfm

55. Quereshi K, Gebbie K, Shoaf K, Soto J, Gebbie EN, Morse SS. Use of the Incident Command System Across Three Sectors of the Healthcare System in the United States. Prehospital and disaster medicine 2005; 20(Supl. 9):1-2.

56. CA EMSA. Hospital Incident Command System: Guidebook. Sacramento: CA EMSA; 2006.

57. U.S. Department of Health and Human Services. Medical Surge Capacity and Capability. Washington: U.S. Department of Health and Human Services; 2007.

Artigo apresentado em 11/04/2014

Aprovado em 10/06/2014

Versão final apresentada em 12/06/2014 